\title{
Walter Benjamin e Paris individualidade e trabalho intelectual
}

\author{
RENATO ORTIZ
}

\begin{abstract}
RESUMO: Este artigo é uma leitura do texto de Walter Benjamin Paris capital do século XIX. A partir do conjunto de anotações que Benjamin faz de diversos livros consultados, principalmente durante sua pesquisa na Bibliothèque Nationale, o autor pretende trabalhar a noção de indivíduo vinculando-a a dois temas. Primeiro, a emergência do flâneur como tradução do espírito de mobilidade que se inaugura com a modernidade. Para isso a discussão sobre a noção de espaço, particularmente no que diz respeito a cidade de Paris, é importante. O flâneur surge assim como um indivíduo desenraizado que se locomove através do espaço urbano remodelado. Segundo, uma aproximação entre o ato da flânerie e o trabalho intelectual. Considerando a flânerie como uma atividade intelectual o autor mostra como os temas do distanciamento e da construção do objeto são relevantes tanto para o flâneur-detetive quanto para a reflexão nas ciências sociais.
\end{abstract}

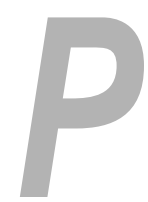

aris capital do século XIX é um livro incompleto, uma obra inacabada ${ }^{1}$. Folheando este conjunto de anotações dispersas e de citações múltiplas, o leitor, auxiliado pelo esforço de montagem dos organizadores, consegue talvez ter uma idéia do esquema de redação do autor, no entanto, a visão que se tem da totalidade do texto é sempre incerta, imprecisa. A margem para dúvidas e interpretações é grande, de uma certa maneira pode-se sempre indagar em que medida Benjamin nos autorizaria, ou não, esta ou aquela inferência. A fragmentação da escrita, as repetições, a superposição de temas, nos encerram na incompletude da obra, deixando uma
UNITERIMOS: Walter Benjamin, indivíduo, cidade, flânerie, ciências sociais, modernidade.

Professor do Departamento de Sociologia do IFCH - UNICAMP 
${ }^{1}$ Utilizo a tradução italiana, Parigi Capitale del XIX Secolo, Torino, Einaudi, 1986.

${ }^{2}$ Carta citada na introdução Cronologia dell' opera e notizie sul testo (Agamben,1986, p. XIV). sensação de arbitrariedade que o trabalho criterioso e diligente dos editores não consegue dirimir. Minha intenção não é porém fazer uma análise integral e rigorosa do livro, se é que podemos chamá-lo assim. Dele sublinho alguns aspectos que me permitem retomar questões que já havia anteriormente abordado em meus estudos sobre a França no século XIX (cf. Ortiz, 1991). Interessa-me perceber como Benjamin compreende as transformações que ocorrem durante este período e em que medida o processo de racionalização da sociedade (para falarmos como Weber) incide sobre o próprio pensamento que se debruça para compreendê-la.

Cabe porém, antes de enfocar a temática que escolhi, situar as intenções do autor. Em 1927, fruto de uma breve estadia em Paris, Walter Benjamin escreve em co-autoria com Franz Hessel um curto artigo sobre As Passagens. O texto, que não foi publicado na época, demonstra sua curiosidade por este novo tipo de arquitetura urbana; entre 1927 e 1929, convencido da importância do tema, ele se dedica a desenvolver uma proposta que denominou de As Passagens de Paris: uma féerie dialética. O encontro com Adorno em 1929 irá alargar seu horizonte de trabalho, o projeto se expande e torna-se mais ambicioso. Rolf Tiedmann, organizador da edição original em alemão (Das Passagen-Werk), considera que a presença de Adorno e Horkheimer foi determinante, são eles que levam Benjamin a se aproximar dos escritos de Marx (cf. Tiedmann, 1989). Isso terá uma influência decisiva na reelaboração do esboço inicial; primeiro, surgem novos temas: hausmannização, combate de barricadas, ferrovias, bolsa de valores, história econômica, além das secções dedicadas a Marx, Saint-Simon e Fourier. Segundo, no próprio tratamento da problemática em curso. O conceito de fantasmagoria, amplamente utilizado por Benjamin, deriva de sua leitura do caráter fetichista da mercadoria. Entretanto, apesar da abertura de novos horizontes, devido a problemas pessoais e políticos, entre 1931 e 1934 o projeto se desacelera, é somente quando Benjamin se exila em Paris que o ritmo de trabalho se intensifica. Ele tem agora à sua disposição o rico material bibliográfico da Bibliotèque Nationale. Em 1935 há uma mudança de rumo. A proposta já não mais se intitula As Passagens mas Paris capital do século XIX. Em uma carta a Scholen, Benjamin justifica a mudança do título ponderando que, analogamente a seu estudo sobre o barroco, no qual tinha desenvolvido seu pensamento sobre o século XVII "a partir da Alemanha", ele gostaria de compreender o XIX "a partir da França"2. O esclarecimento merece uma atenção especial pois nos remete ao conceito de alegoria. Sabemos que a alegoria é uma figura de linguagem na qual diz-se uma coisa para significar outra. Esta técnica é muito utilizada por Benjamin quando escreve Origem do drama barroco alemão. Mas qual seria esta "outra coisa" significada através do barroco? Em seus comentários à obra benjaminiana Sérgio Paulo Rouanet responde: "em essência, a alegoria barroca remete a uma coisa última, referente unitário que engloba todas as significações parciais: a história" (Rouanet, 1984, p. 38). Isto é, a uma concepção de história dominante na Alemanha durante o século XVII. O barroco denota assim uma outra coisa; através dele, é possível captar situações, uma sensibi- 
lidade artística, uma maneira de "estar no mundo" característica de um momento histórico. $\mathrm{O}$ mesmo pode ser dito em relação a Paris. Talvez tenha sido a proximidade a Baudelaire que tenha permitido a Benjamin conceber a que ponto a cidade, no seu todo, pode constituir-se num objeto alegórico. Cito duas passagens sugestivas a esse respeito: "O talento de Baudelaire, nutrido com melancolia, é um talento alegórico. Tout pour moi devient allégorie. Com Baudelaire, pela primeira vez Paris torna-se objeto da poesia lírica" "Na poesia de Baudelaire o motivo da morte funde-se com a imagem de Paris. Os Tableaux parisiens, o Spleen de Paris, Excursus sobre os elementos arquitetônicos da cidade de Paris" (Benjamin, 1986, p. 49). Centrar a análise sobre a cidade, sua configuração, seus eflúvios, sua atmosfera, significa revelar algo que nela está contido mas que a transcende. Neste sentido pode-se compreender, "a partir de Paris", os mecanismos estruturantes da modernidade do XIX. Se isso é verdade permanece uma dúvida: porque o autor abandona a metáfora das passagens para substituí-la por outra?

Não é difícil perceber que as passagens têm também, em diferentes anotações ao longo do livro, um valor alegórico. Nas páginas de um Guia Ilustrado de Paris pode-se ler o seguinte comentário: as passagens formam um "mundo em miniatura" no qual oflâneur pode encontrar "tudo" o que necessita (Benjamin, 1986, p. 77). "Mundo" contendo elementos diversos, parcelas de realidade a serem decodificadas pelo olhar atento do intérprete. Uma outra referência reforça o aspecto em questão. "Balzac assegurou a constituição mítica de seu mundo determinando-o através de seu contorno topográfico. O terreno de sua mitologia é Paris. Paris com seus dois ou três banqueiros, Paris com o grande médico Horace Bianchon, o empreendedor César Birotteau, com suas quatro ou cinco cocottes, o usurário Gobseck, o pequeno grupo de advogados e de militares. O que conta é que os personagens deste circuito são comparsas nas mesmas ruas, nos mesmos ângulos, nos mesmos quartos escuros. Isso significa que a topografia delineia o espaço mítico da tradição, e, da mesma forma como para Pausania ela tornou-se a chave para a compreensão da Grécia, as passagens seriam a chave deste século no qual Paris se enraíza" (Benjamin, 1986, p. 129). as passagens exprimiriam assim "todo" o século XIX, elas constituiriam a chave de sua compreensão. Creio no entanto que Benjamin pouco a pouco se dá conta da fragilidade desta proposição inicial. A Paris de Balzac é muito distinta da Paris de Baudelaire. A distância que se interpõe entre elas é preenchida pelas transformações urbanísticas, pelo advento da luz elétrica e dos bondes, pela invenção do cinema e dos novos estilos arquitetônicos em ferro e vidro, estações ferroviárias e grand-magasins. Com o passar dos anos Paris se metamorfoseia afastando-se de seu passado arraigado ao Antigo Regime. O esplendor das passagens tem ainda uma vida curta confinando-se ao período que vai do final dos anos 20 ao início dos $50^{3}$. Seria pouco plausível eleger como argumento central de análise um elemento em decadência. Benjamin, ao renomear seu projeto, desloca suas preocupações para uma totalidade que contém em seu bojo traços nodais para ser a "capital do século XIX", ou melhor, um palco no qual se encenaria o drama da modernidade.
3 "Razões do declínio das passagens: calçadas alargadas, luz elétrica, transformação da prostituição, cultura de áreas abertas" (Benjamin, 1986, p. 136). 
ORTIZ, Renato. Walter Benjamin e Paris - individualidade e trabalho intelectual. Tempo Social; Rev. Sociol. USP, S. Paulo, 12(1): 11-28, maio de 2000.

Uma alegoria é no entanto algo abstrato, para apreendê-la é necessário amarrar a análise a elementos mais concretos. Benjamin irá encontrá-los em temas como: iluminação a gás, sistema ferroviário, passagens, eletricidade, fotografia, folhetim, magasins de nouveautés, grand magasins, etc. Sua escolha de assuntos aparentemente díspares não é casual, eles constituem objetos heurísticos que alegoricamente exprimem uma "realidade". Paris tornase assim um "mundo em miniatura". A estratégia benjaminiana privilegia portanto os "pequenos" objetos. O que lhe prende a atenção são o traçado e os nomes das ruas, as catacumbas, as edificações, como as pessoas se vestem, comem e vivem. Há algo de Simmel neste olhar posicionado ao lado dos indivíduos e da paisagem. As relações sociais são captadas no fluir do dia a dia. Pode-se entender o estilo de Benjamin como uma proposta de contraponto a uma forma mais abstrata de trabalhar os laços sociais, ponto de vista que privilegiaria o que muitos historiadores denominam atualmente de "vida cotidiana". Nas edições alemã e francesa do livro, Rolf Tiedmann chama a atenção para este aspecto da démarche benjaminiana. Tudo se passa como se ele deixasse se envolver por um "doce empirismo" abandonando o pensamento à singularidade dos objetos. Visto assim seu enfoque se encontraria na contracorrente de uma filosofia mais acadêmica (é desta forma que muitos autores entendem o contraste entre Benjamin e Adorno) ou de uma perspectiva sociológica macro cujo interesse focalizaria muito mais as estruturas do que propriamente o dinamismo das interações sociais. Entretanto, é preciso ter claro que a temática do cotidiano não é apenas fruto de uma construção intencional do autor, de sua postura filosófica, ela permeia o próprio material por ele utilizado. É suficiente folhearmos os textos citados ao longo do livro: Quandj'étais photographe (Nadar, 1900), La photographie au salon de 1859 (Figuier, 1989), Histoire de la publicité (Datz, 1894), Ce qu'on voit dans les rues de Paris (Fournel, 1858). Sem nos esquecer dos diversos escritos de Georges D' Avenel sobre "os mecanismos da vida moderna", eles falam de alimentação, transformação do comércio, advento do transporte urbano, pu-

${ }^{4}$ Cito ao acaso alguns desses artigos: Vicomte Eugène Melchior de Vogué, A travers l'exposition: les portes, la tour $\left(1^{\circ}\right.$ de julho 1889); J. Fleury, L'eau a Paris (15 de setembro 1892); Maurice Talmeyr, L'âge de l'affiche ( $1^{\circ} \mathrm{de}$ setembro 1896); Lazare Weiller, La suppression des distances (15 de julho 1898).

5 Uma interessante antologia de textos da época foi organizada por Oster e Goulemot (1989). blicidade, estações de trem, esgotos, etc. (cf. D’ Avenel, 1896). Trata-se de um tipo de literatura, de crônica escrita na primeira pessoa, na qual a cidade se revela nas suas entranhas. Nela se encontram inseridos os indivíduos com seus modos de vida, seus medos e desejos. Basta olharmos as publicações da época para percebermos a que ponto os temas elaborados por Benjamin se sobrepõem aos assuntos por elas descritos; por exemplo, na Revue dês Deux Mondes encontramos artigos sobre o luxo, a distribuição da água em Paris, as exposições universais, o telégrafo sem fio, a hora legal, a iluminação elétrica, etc. ${ }^{4} \mathrm{O}$ ensaísmo do século XIX mobiliza a imaginação de literatos, jornalistas, fotógrafos, filósofos e críticos de arte. Paris, no seu dia a dia, é tematizada nos seus múltiplos aspectos 5 . A forma de escrita desses autores desenvolve-se ao sabor da idiossincrasia de cada um, ela nada tem de "universitária" e dificilmente poderia se encaixar nas exigências de uma ciência social que ainda mal existia. (a sociologia e a história estavam em processo de estruturação como campos autônomos de saber). O ensaísmo sobre "a vida cotidiana" era a linguagem 
dominante na qual se expressava a maioria dos escritores da época. Benjamin, ao reapropriar-se deste legado bibliográfico, irá certamente resignificá-lo, masé difícil dizer que entre sua proposta e o material disponível existe uma ruptura, pelo menos temática. Benjamin bebe na fonte da Bibliotèque Nationale para, aí sim, elaborar sua interpretação pessoal.

É possível, mesmo de maneira imprecisa, datar o período no qual se desenrola o enredo de Paris capital do século XIX. Metaforicamente, utilizando as anotações do autor, eu diria que ele se estende de 1828, quando circula o primeiro ônibus ligando a Bastille à Madeleine, a 1913, momento em que o último bonde puxado a cavalo é definitivamente superado pela tração motora (cf. Benjamin, 1986, p. 554). Entre uma ponta e outra Paris passa por mudanças profundas, sua história, marcada por diferentes cadências, revela como o ritmo lento dos cavalos é substituído pela velocidade dos automóveis e dos bondes elétricos. Não diz Benjamin que ainda em 1839 era elegante as pessoas passearem acompanhadas de tartarugas pelas calçadas (cf. Benjamin, 1986, p. 552) (o que exprime o andar vagaroso do flâneur)! A rigor, talvez fosse esclarecedor distinguir entre dois séculos XIX, duas modernidades. O primeiro é fruto da Revolução Industrial: advento do vapor e das ferrovias, mecanização das fábricas, crescimento da indústria, criação de grandes empresas industriais e comerciais, desenvolvimento do patronato e do proletariado, migração rural, crescimento das cidades. Entre a Restauração e o início do Segundo Império a sociedade francesa conhece uma transformação radical. Não é por acaso que Louis Chevalier escolhe este período para estudar as classes perigosas (cf. Chevalier, 1984). É no interior de uma Paris superpovoada, sufocante e miserável (tão bem descrita por Victor Hugo) que ele pode retratar a existência da classe trabalhadora. O florescimento da nova ordem econômica e social pode ser ainda captado de maneira viva através da discussão sobre as "duas Franças". Entre 1822 e 1836 governantes e políticos franceses opõem uma França do Norte, industrializada, moderna, urbana, a uma França do Sul, agrícola, tradicional, atrasada (cf. Chartier, 1978). Caberia à parte "esclarecida" levar o progresso para os confins do país onde predominavam ainda as forças "obscuras" do passado. As transformações da sociedade francesa têm implicações na esfera cultural e social. A invenção da daguerreotipia em 1839 impulsiona o mercado de retratos, fonte constante de atrito entre fotógrafos e pintores. O desenvolvimento da imprensa, com as inovações técnicas e comerciais (introdução de um novo sistema de impressão e da publicidade como fonte obrigatória de lucro dos jornais), dá origem ao romance-folhetim, gênero que se populariza sobretudo entre as leitoras femininas (nesta esfera um outro conflito, mobilizando escritores versus jornalistas, se instaura). O comércio de varejo conhece também sua "revolução". O fim das corporações elimina as vantagens que os alfaiates detinham na determinação do preço das roupas. Surge assim a figura do negociante transformador. Eles compram tecidos em grande quantidade, utilizam a mão de obra 
terceirizada das costureiras, distribuem as mercadorias para os novos estabelecimentos. O surgimento dos magasins de nouveautés nas décadas de 30 e 40 exprime este movimento de renovação do comércio (cf. Faraut, 1983). Aí se vendiam tecidos e artigos de luxo: roupas, sedas, peças de lã, lençóis, botões, luvas, ocasionalmente peles e guarda-chuvas. Dentro do espírito da época, o agrupamento de mercadorias tão diversas era uma novidade; ele rompia com a especialização dos pequenos comerciantes tradicionais. Em 1855 um Guia de Paris dizia: "O que antes era preciso comprar em trinta lojas, atualmente encontra-se reunido em vastas galerias, com seções de objetos para a vestimenta e para a casa, desde o vestido ao boné confeccionado, das luvas aos guarda-chuvas" (citado em Jarry, 1948, p. 27). As novas lojas implantam ainda uma mudança na apresentação das mercadorias, introduzindo exposições por seções e balcões especializados por ramos de produto. Elas permitem também a livre circulação dos clientes no seu interior estimulando desta forma uma nova prática social: fazer compras.

O segundo século XIX se distancia da Revolução Industrial para se apoiar num outro sistema técnico: telégrafo sem fio, eletricidade, automóvel, indústria química, cinema, etc. (cf. Gille, 1978; Morsel, 1983). Por isso os economistas falam, a partir de 1880, de uma "segunda revolução industrial" a indústria descola da agricultura, no interior do setor industrial diminui a produção de bens de consumo (têxtil, alimentos) em benefício da produção de equipamentos, desenvolvimento das indústrias vinculadas às cidades (água, eletricidade), da indústria de metais (ligas) e produção de energia. Os historiadores franceses tendem a concordar que, a partir de meados do século, o ritmo da história social se modifica (cf. Agulhon, 1983). O termo em si é impreciso - "meados do século" - mas quando lemos sobre as diversas áreas específicas (econômica, demográfica, urbana, técnica), parece haver uma convergência no sentido de se localizar, dentro dos limites dessa duração, senão uma ruptura, pelo menos uma aceleração. O corte "meados do século" pode ser ainda encontrado no setor das comunicações; não é por acaso que se fala também em um "segundo momento da história das ferrovias". Uma das dificuldades na implantação das estradas de ferro na França dizia respeito à indefinição sobre quem deveria construí-las. Até 1839 os empreendimentos estavam reservados ao capital privado mas devido a múltiplos fatores a maioria das companhias não conseguiram cumprir suas promessas. Em 1842, após uma polêmica entre o setor privado e o Estado, chega-se a um acordo para se estabelecer o mapa ferroviário francês. Porém, os acontecimentos políticos de 1848 e a crise econômica irão retardar novamente a realização dos projetos. É somente no decorrer do Segundo Império que as grandes companhias conseguem equacionar seus problemas; durante a Terceira República as ferrovias se expandem e, pela primeira vez, passam a integrar um sistema nacional de comunicação. Para se ter uma idéia: em 1847 a quilometragem explorada era de apenas $1.832 \mathrm{~km}$, em 1908 ela atinge $40.239 \mathrm{~km}$, transportando um volume de 16 milhões de passageiros por quilômetros (cf. Levasseur, 1912).

Evidentemente a distinção entre dois séculos XIX é puramente 
ORTIZ, Renato. Walter Benjamin e Paris - individualidade e trabalho intelectual. Tempo Social; Rev. Sociol. USP, S. Paulo, 12(1): 11-28, maio de 2000.

analítica, muito da primeira modernidade se prolonga até a segunda (iluminação a gás, no transporte urbano a tração a cavalo, etc.). Mas ela é útil na medida em que nos permite compreender como qualitativamente a segunda modernidade se estrutura sobre bases materiais distintas da anterior. Um exemplo significativo é o surgimento dos grand magasins. A passagem dos magasins de nouveautés para os grand magasins corresponde a uma nova fase do capitalismo francês (cf. Bergeron, 1983; Miller, 1987). Ela vinculase a transformações econômicas importantes e às mudanças que se dão nos transportes (estradas de ferro), no sistema bancário e nos negócios. Isso implicou na criação de mecanismos mais sofisticados de vendas e na gestão de grandes espaços nos quais as mercadorias pudessem ser expostas e exibidas para o grande público. As novas lojas de departamentos ultrapassam os antigos estabelecimentos comerciais em dois pontos: a dimensão arquitetônica e o volume de negócios. Como empresas industriais elas funcionavam a base de uma rápida rotação dos estoques, o que lhes permitia praticar uma política de preços mais atrativa. O volume de vendas possibilitava ainda uma maior diversificação dos artefatos: confecção, brinquedos, papelaria, etc. A estratégia comercial, calcada na publicidade de "massa" (a rigor dirigida para as classes médias mais abastadas), requeria ainda a mobilização de uma "multidão" - algo em torno de quinze a dezoito mil pessoas entravam e saíam diariamente do Bon Marché e do Louvre. Para abrigar toda essa gente os arquitetos tiveram de construir espaços deliberadamente concebidos para a exposição e a venda de mercadorias. Arquitetura em ferro e vidro capaz de superar os inconvenientes das construções de pedra pois uma das características do novo estilo arquitetônico foi a criação de grandes vãos que lembravam as antigas catedrais góticas ${ }^{6}$.

A cadência desses dois séculos XIX transparece claramente no texto de Benjamin. Há várias formas de marcá-la. Primeiro, a superação das passagens. A esse respeito, uma citação, retirada de um livro de Jules Claretie, La vie à Paris 1895, é sugestiva: "Em Paris... as passagens que estiveram tanto tempo na moda, delas as pessoas fogem como se sentissem enclausuradas. A passagem, que foi para o parisiense uma espécie de salão - lugar onde se fumava, se conversava, hoje nada mais é do que um abrigo do qual nos lembramos quando chove. Algumas passagens, por causa da celebridade desta ou daquela loja que aí se encontra, guardam ainda uma certa atração. Mas é o renome do locatário que prolonga a voga, ou melhor, a agonia do lugar. Para os parisienses modernos as passagens têm um grande defeito; pode-se dizer delas o mesmo que de certos quadros de perspectiva sufocante: falta ar'(Jules Claretie apud Benjamin, 1986, p. 176). Fechamento, falta de ar. As qualificações procedem. As passagens exprimem uma modernidade contida, uma intenção de mudança restrita a uma urbanidade ainda compartimentada. Como nos lembra Philippe Ariès, até a segunda metade do século XIX, a velha Paris era constituída por uma rede densa de pequenas células autônomas mas sem relação entre elas (cf. Ariès, 1971). Cada zona da cidade era um mundo, um universo sem comunicação com os outros. As passagens conseguiam no má-
Anota Benjamim: "Transformação das lojas internas das passagens em lojas de departamento. Princípio da loja de departamento: o plano forma um espaço único. Pode-se abraçá-lo com um único olhar" (Benjamin, 1986, p. 84). 
ximo estabelecer um contato entre uma rua e outra mas dificilmente poderiam ser tomadas como a expressão de ruptura desses "mundos" estanques. É apenas com as intervenções de Haussmann que Paris transforma-se numa cidade moderna, isto é, num todo integrado. Hausmann racionaliza o espaço urbano, traça ruas, avenidas, pontes, praças, interligando os pontos nevrálgicos da urbes. Um eixo norte-sul, leste-oeste, comunica o centro à periferia, e as grandes vias de comunicação convergem para as estações de trem. Hausmann inventa o boulevard multiplicando a escala urbanística até então conhecida (ruas com mais de 30 metros de largura). Não se pode esquecer que até 1828 Paris não dispunha de nenhum tipo de transporte público. No entanto, mesmo após essa data, as várias sociedades criadas para explorar a locomoção citadina tinham apenas uma existência rudimentar. O número de carros disponíveis era pequeno, o trajeto percorrido irregular e o serviço oferecido descontínuo. Somente em 1855 foi fundada a Companhia Geral de Ônibus cujo objetivo era unificar o transporte público. As reformas urbanísticas e a generalização dos meios de transporte fazem com que a cidade possa ser concebida como um sistema integrado. A noção de circulação se sobrepõe assim à de fixidez. Mas para isso a velha Paris teve de ser destruída. Um testemunho recolhido por Benjamin diz: "Paris deixou de ser para sempre um conglomerado de pequenas cidades que tinham sua fisionomia própria, sua vida, onde se nascia e se gozava a vida, lugar do qual não se sonhava partir, onde a natureza e a história tinham colaborado para realizar a variedade na unidade". E o autor acrescenta, "na sua cidade transformada numa encruzilhada cosmopolita, o parisiense tornou-se um ser desenraizado"(Benjamin, 1986, p. 185). A passagem marca dois aspectos de um mesmo fenômeno: o fim do isolamento no interior da cidade e o desenraizamento do indivíduo de sua territorialidade local. Os dois movimentos se completam. Na medida em que caem as antigas barreiras, em que as ruas se expandem, a mobilidade das pessoas se intensifica. Como comenta um autor da época: "Nossas ruas mais largas e nossas calçadas mais espaçosas tornaram mais fácil a doce flânerie, impossível para nossos pais, a não ser nas passagens" (Benjamin, 1986, p. 79). O ritmo da história dilata e acelera os passos do transeunte. Entretanto, o que se ganha em locomoção necessariamente não se traduz em liberdade ou emancipação. O segundo século XIX desnuda as imposições de um mundo capitalista cujos tentáculos se estendem sobre a vida cultural. Benjamin capta muito bem este aspecto quando contrasta As passagens ao grand magasin. As passagens, em sua modernidade restrita, ofereciam ao passante uma possibilidade de deslocamento ainda não inteiramente imerso nas malhas da racionalidade comercial. As mercadorias expostas nas vitrines atiçavam seu apetite de consumo mas essas "ruas sensuais do comércio" eram enclaves incrustados em poucos lugares da cidade. Entre o apelo e a realização do ato propriamente dito faltava um elo: a revolução dos transportes, a redefinição do comércio, a renovação urbana, a transformação das finanças. É somente com o advento das lojas de departamento que "pela primeira vez o consumidor começa a se sentir massa"(Benjamin, 1986, p. 87). Ou ainda: "A identificação com a mercadoria 
é fundamentalmente uma identificação com o valor de troca. O flâneur é o homem virtuoso desta identificação. Ele põe em movimento o conceito de venalidade. Assim como a loja de departamento é sua última aventura, o homem-sanduíche é sua última encarnação"(Benjamin, 1986, p. 582-583).

O segundo século XIX se apresenta assim sob o signo de uma modernidade comprometida. Nela, o indivíduo cede lugar à multidão. O termo em si é sugestivo pois caracteriza o debate de toda uma época. Ele significa primeiro produção em massa. A Revolução Industrial redefine as relações produtivas, a fábrica torna-se o centro das atividades de uma sociedade que rompe com os laços tradicionais. Isso tem implicações em diversos setores da vida social, da confecção, padronizando a fabricação das vestimentas e influenciando a moda, à imprensa, que passa a se organizar segundo critérios de eficiência técnica e produtiva voltada agora para uma difusão de "massa" (a rigor isso ocorre somente no final do século quando jornais do tipo Le Petit Parisien tem uma tiragem de mais de um milhão de exemplares). Assim, vários bens (esgoto, água, gás, eletricidade, etc.), antes restritos a uma camada privilegiada de pessoas, pouco a pouco são difundidos no conjunto da população (movimento que se completa no século XX). As comodidades, como se dizia no Antigo Regime, antes vistas como objetos e serviços de luxo, com o processo de mecanização, tornam-se cada vez mais acessíveis às diferentes classes e camadas sociais. Mas multidão possui ainda um outro significado: o termo se contrapõe ao de individualidade. Na aglomeração das grandes metrópoles ela absorve os traços de singularidade integrando o indivíduo à massa anônima de pedestres. Anota Benjamin a esse respeito: "A massa em Baudelaire. Distende-se como um véu diante do flâneur: é a última droga do solitário. Suprime portanto todo sinal de singularidade: seu último asilo é no meio do bando"(Benjamin, 1986, p. 579). Aglomeração, bando, como é possível a singularidade neste contexto? A multidão expressa uma concentração, um volume localizado num determinado espaço físico. Ela é portanto homogênea. Nela, toda heterogeneidade se dilui em benefício do todo, do anonimato. A multidão é inimiga da diversidade, tema amplamente explorado por Gustave Le Bon e Gabriel Tarde (cf. Le Bon, 1980; Tarde, 1989). Benjamin o retoma de outra maneira, por um viés marxista. Como as mercadorias que podem ser reduzidas a um mesmo denominador comum, o dinheiro, "equivalente universal", os indivíduos, no processo de consolidação da lógica capitalista, se fundem a um mesmo padrão transformando-se em massa. O flâneur torna-se assim mercadoria. Uma referência ao livro de Edmond Jaloux, Le Dernier Flâneur, é neste ponto expressiva: "Um homem que passeia não deveria se preocupar com os riscos que corre ou com as regras de uma cidade. Se algo divertido lhe vem ao espírito, se uma loja curiosa cruza o campo de sua visão, é natural que, sem enfrentar os perigos que nossos antepassados jamais suspeitaram, ele queira atravessar a rua. Ora, hoje ele não pode fazê-lo sem tomar mil precauções, sem antes interrogar o horizonte, sem pedir licença à prefeitura de polícia, sem se misturar com um rebanho agitado e atordoado, para o qual o caminho já se encontra traçado de antemão pelo brilho do vil 
Numa das citações compiladas lê-se: "Não vamos condundir o flâneur com o badaud... O flâneur tem sempre plena posse de sua individualidade. Pelo contrário, a do badaud é absorvida pelo mundo exterior... Sob a influência do espetáculo o badaud torna-se impessoal; ele já não é mais um homem: ele é público, multidão". (Fournel, 1858 apud Benjamin, 1986, p. 559). metal. Antigamente, seus irmãos os badaud, que caminhavam tranqüilamente pelas calçadas, e paravam em todos os lugares, davam a este fluxo humano uma certa delicadeza e tranqüilidade que foi perdida. Agora é a torrente na qual você é engolfado, apertado, jogado à torto e a direito". No final do XIX, o flâneur da primeira modernidade, acostumado ao ritmo lento das passagens, encontra dificuldade em se deslocar. A circulação pela cidade tornou-se certamente mais fácil e mais rápida, as ruas e o sistema viário lhe permitem locomover-se sem maiores problemas, mas as imposições externas são também mais coercitivas, cada vez mais ameaçam sua liberdade individual.

Logo no início de seu livro, Ce qu'on voit dans les rues de Paris, publicado em 1858, Victor Fournel nos interpela a partir do conto de Edgar Allan Poe O homem da multidão (cf. Fournel, 1858). Num diálogo imaginário com o leitor o autor confessa sua intenção, transformar-se num personagem de Poe e traduzir para ele o que vê perfilar diante de seus olhos. Victor Fournel quer inclusive inventar uma "teoria do flâneur" e para isso procura cuidadosamente discernir entre sua atitude e a do badaud'. O homem que se desloca no meio da multidão o faz impulsionado por sua curiosidade intelectual, ele deliberadamente toma a decisão de conhecer, de escolher os caminhos, para apreender, como uma máquina fotográfica, os pequenos detalhes da vida cotidiana. O badaud erra inconscientemente pela cidade, mendigo ou pedestre, ele é matéria prima que constitui a "massa", elemento homogêneo que flui pelas artérias urbanas. A proposta de Fournel é sugestiva pois reflete sobre um personagem urbano até então desconhecido na cidade de Paris. Sua resposta isola ainda um outro elemento, a liberdade de consciência, como fator constitutivo do ato da flânerie.

Sociologicamente, a pergunta que se pode fazer é a seguinte: porque o flâneur surge apenas no século XIX? Quais são as transformações que permitem o seu advento? Embora Benjamin não formule explicitamente a questão, a resposta encontra-se ao longo de toda sua obra: ele é fruto da modernidade. As sociedades do Antigo Regime eram formadas por conjuntos compartimentados. Neles, a circulação de pessoas, mercadorias, idéias, objetos, foi sempre restrita. A estabilidade da ordem estamental requeria esta compartimentação dos "mundos" e o cerceamento da mobilidade, limites que separavam as classes sociais, a cidade do campo, a cultura erudita da cultura popular. Antes da Revolução Industrial, das transformações políticas, e do Estado-nação, cada país era constituído por uma série heterogênea de regiões, de universos não integrados numa mesma totalidade. Paris, apesar de ser o centro da corte, traduzia na sua urbanidade esta contenção espacial. Já em 1783 a Secretaria da Fazenda havia proposto a construção de um novo muro para envolvê-la completamente. As antigas muralhas, edificadas na Idade Média, há muito haviam sido ultrapassadas pela expansão da cidade. O intuito era que as novas portas (hoje meros nomes de estações de metrô) conseguissem regular o fluxo de pessoas e de mercadorias. Barreira material - pretendia-se controlar os impostos locais (Polanyi nos lembra que o surgimento de um mercado unificado nacional é fruto do século XIX) -, elas simboliza- 
vam como cada lugar, cada região, se via como uma unidade fechando-se ou abrindo-se para o mundo existente "lá fora". Mas vimos ainda como dentro de Paris esta segmentação se reproduzia. A circulação entre um bairro e outro, o deslocamento das pessoas, era bastante reduzido. Os estudos mostram que o quartier funcionava como uma unidade de trabalho, de comércio, religiosa e de lazer (cf. Galabrun, 1983). Fora as profissões que exigiam uma certa mobilidade, magistrados, médicos, tabeliões, a maioria da população encontrava-se presa à sua localização territorial. A nova organização social, fundada na indústria, rompe com esses constrangimentos promovendo o intercâmbio entre espaços até então voltados sobre si mesmos. A circulação, princípio estruturante da modernidade, possibilita a emergência do flâneur. Enquanto indivíduo, isto é, cidadão que vê seus direitos afirmados somente após a Revolução Francesa, ele pode escolher seu destino sem se atrelar à sua origem estamental. Desenraizando-se de sua territorialidade ele pode caminhar, mover-se segundo os objetivos traçados por sua consciência individual.

Mas o que faz oflâneur? Olha e descreve. Personagem urbano, suas antenas sensoriais privilegiam a visão, sentido associado por Simmel às qualidades desenvolvidas pelos indivíduos na grande metrópole. Para ele a cidade é uniforme apenas na aparência, sob ela se esconde todo um mundo, realidade subterrânea ao cotidiano do homem ordinário. Diz Benjamin: "Reconstruir topograficamente a cidade, dez, cem vezes, através das passagens e das portas, dos cemitérios e dos bordéis, das estações de trem... como antigamente podíamos fazê-lo através das igrejas e dos mercados. Os vultos mais secretos da cidade situam-se na sua parte mais recôndita" (Benjamin, 1986, p. 130). A cidade se apresenta assim como um labirinto, espaço cheio de surpresas, porém, só o olhar perspicaz capta o que subjaz à sua manifestação epidérmica. Observa-se o inesperado, o não corriqueiro ${ }^{8}$. Este é o traço distintivo entre o flâneur e o homem que deambula pelos mesmos caminhos por ele percorrido. A flânerie pressupõe portanto a idéia de distanciamento. Para compreender o que se vêé necessário que o observador se separe do que está sendo observado. Neste ponto, uma primeira aproximação pode ser feita com o viajante. A viagem é sempre um deslocamento através de espaços descontínuos. Aquele que viaja sai de "seu" território, de um mundo que lhe é familiar, para encontrar "outros" lugares, distantes, separados de sua vivência anterior. $O$ viajante é um estrangeiro, alguém à parte do universo descrito pelo relato da viagem. De alguma maneira o flâneur partilha com ele sua condição de exterioridade. Baudelaire dizia que "para o verdadeiro flâneur é um imenso prazer habitar o indeterminado, o provisório... Estar fora de casa, e por isso sentir-se em casa em qualquer lugar; ver o mundo, ser o centro do mundo e permanecer escondido do mundo, esses são alguns dos prazeres desses espíritos independentes, apaixonados, imparciais... O observador é um príncipe que goza de sua condição incógnita” (Benjamin, 1986, p. 576). Existem no entanto algumas discrepâncias que merecem ser sublinhadas. Para o viajante, a condição de estranhamento está contida no próprio ato do deslocamento. O ponto de partida do olhar encontra-se imediatamente afastado dos dados coligidos. Quem observa é naturalmente um estranho. O
${ }^{8}$ Uma das anotações diz: "Em nosso mundo uniformizado é no próprio lugar, e em profundidade, que se deve ir; o dépaysement e a surpresa, o exotismo o mais potente, está ao lado" (Daniel Halévy apud Benjamin, 1986, p. 576-577). 
flâneur deve compreender um elemento do qual ele é parte integrante pois viaja sem sair do lugar. Para ele a cidade é moradia e paisagem. Moradia porque aí ele habita, ele nela se insere como um nativo; paisagem pois a proximidade do quadro que o envolve deve ser apreciada à distância. Por isso torna-se necessário construir mecanismos de estranhamento que o desenraizem de sua percepção imediata das coisas. Neste sentido, ele se assemelha ao sociólogo. Para entender sua própria cultura ele necessita precaver-se contra o habitualmente conhecido, isto é, o senso comum. Todo seu esforço se concentra na elaboração de artifícios que lhe permitam "sair" do mundo que pretende apreender. Sem isso sua visão perderia em nitidez.

A flânerie é pois uma atividade intelectual. Em Benjamin isso se exprime através de duas metáforas, o caçador e o detetive. "Estudioso e caçador, o texto é uma selva na qual o leitor é caçador" (Benjamin, 1986, p. 992). A cidade-labirinto, no emaranhado de sua sinuosidade, se apresenta como um texto espesso, este é o terreno no qual opera a razão que o decifra. Ela segue as pegadas para descobrir o verdadeiro lugar da caça. O mesmo movimentoé percorrido pelo saber detetivesco. Na verdade, "a figura do flâneur anuncia a do investigador"'(Benjamin, 1986, p. 574). Afinal os dois partilham o mesmo talento, revelar o que se esconde por detrás da realidade aparente. Na sua origem o romance policial é muito distinto de sua versão cinematográfica atual. Nele, a mente comanda a ação, e não os músculos como no estereótipo hard-boiled inventado por Hollywood. Privilegia-se assim o espírito de observação. Como bem o demonstra Régis Messac, o nascimento do romance policial é resultado do cruzamento de duas dimensões: urbanidade e racionalidade (cf. Messac, 1972). A complexidade da trama necessita da existência de uma sociedade moderna na qual a população se concentra dentro de volumes espaciais relativamente restritos, onde todos se observam uns aos outros, e no qual a perseguição da polícia se desdobra em esconderijos que muitas vezes escapam à sua autoridade (não foi por acaso que os primeiros projetos de numeração das casas de Paris foram uma iniciativa da polícia. A medida racionalizadora visava justamente reforçar o seu controle) (cf. Pronteau, 1966). Por isso o tema da multidão encanta tanto a Poe, nela o assassino se esgueira oculto pelo manto homogêneo que o protege. Mas o romance policial é também contemporâneo da difusão do pensamento científico. O século XIX vê surgir inúmeros movimentos que tomam a ciência, ou melhor, sua vulgarização, como referência fundamental, por exemplo, o mesmerismo, a racionalização do mundo dos espíritos (Allan Kardec), a religião universal de Auguste Comte, o hipnotismo como atração popular. Racionalismo validado pelas inovações tecnológicas: fotografia, cinema, ferrovias, máquinas agrícolas. As exposições universais desempenharam um papel fundamental neste processo de consagração e de legitimação da ciência e da técnica (cf. Ory, 1982). Os literatos têm assim à sua disposição um novo modelo para a construção do personagem central da narrativa detetivesca. Seu método de conhecimento utiliza a dedução a partir das provas materiais encontradas nos locais do crime, e a indução que lhe permite abstratamente articulá-las à resposta correta 
para a solução do problema. Nas palavras de Sherlock Holmes: “A partir de uma gota d'água, um lógico pode inferir a possibilidade de um Atlântico ou de uma Niágara, sem ter visto ou ouvido falar deles. A vida é uma grande cadeia, conhece-se sua natureza desde que nos seja mostrado um simples elo deste encadeamento"(citado em Ousby, 1997, p. 48). O detetive é portanto um especialista na observação dos detalhes, em seu métier a razão é ferramenta essencial na elucidação dos mistérios. Como qualquer cientista social ele deve lutar contra a ilusão da transparência do real (cf. Bourdieu, Passeron \& Chamboredon, 1973). Sua metodologia apóia-se na construção paciente de uma cadeia interpretativa que foge à descrição superficial dos fatos.

Mas a flânerie é ainda uma arte, o que reforça sua aproximação com o trabalho intelectual. Vimos como o flâneur se define a partir de um duplo desenraizamento, de sua condição estamental e de seu local de moradia. Qualidades que o associam a um outro personagem: o boêmio. Diz um desses escritores citados ao longo do livro: "Entendo por boêmios esta classe de indivíduos que não se encontram em nenhum lugar e que se encontram em todos os lugares. Que não possuem um estado único mas exercem cinqüenta profissões; que a maioria deles levanta-se de manhã sem saber onde irão jantar à noite; ricos hoje, famintos amanhã"(Benjamin, 1986, p. 558). O boêmio caracteriza-se por sua mobilidade, vive entre as classes sociais, não pertence a nenhuma delas, e não se fixa permanentemente em nenhum lugar (erroneamente acreditava-se que ele era oriundo da Boêmia e seu nomadismo um traço herdado dos ciganos). Entretanto, ser boêmio não é uma condição, mas uma eleição pessoal, uma maneira de se colocar à margem da sociedade contrapondo-se aos valores dominantes (por exemplo, na pintura o repúdio às instituições tradicionais como as academias). O universo da boêmia, que em Paris envolve, literatos, teatrólogos, fotógrafos, pintores, encerra portanto uma visão de mundo: valorização da individualidade e das qualidades artísticas, recusa dos ideais burgueses. Muito da literatura escrita sobre oflâneur provém deste meio social no qual se cultiva um comportamento "à esquerda" dos cânones estabelecidos. Não se pode esquecer que o conceito de "artista" enquanto indivíduo dotado de um gênio criador é um produto do século XIX. Somente após a Revolução Industrial a arte é concebida como uma "realidade superior" na qual se expressa a idiossincrasia estética de cada um (cf. Williams, 1958). A metáfora da boêmia, enquanto desenraizamento, não fixação às normas, revela justamente este traço de um individualismo consciente. Como se pode ler numa das anotações de Benjamin: "Sair quando nada nos força a fazê-lo, seguir nossa inspiração como se o fato de virar à direita ou à esquerda constituísse em si um ato poético" (Benjamin, 1986, p. 567). Inspiração, liberdade, arte, escolha. Os termos se encadeiam. Mas não devemos pensar que este ato "impensado" seja um ato "desinteressado". Pierre Boudieu tem razão quando diz que a escolha artística está fundada em critérios muito claros: os interesses estéticos (cf. Bourdieu, 1996). Da mesma forma eu diria que a escolha do flâneur não está isenta de intenções, na verdade, ela apenas se apresenta como tal. Ao distinguir sua atividade das outras, em particular do ho- 
mem da multidão, ele afirma uma vontade específica: conhecer uma realidade que se subtrai à percepção da maioria das pessoas. "Virar à direita" ou "à esquerda", nada tem de gratuito, trata-se de um ato cujo objetivo foi previamente traçado. Neste sentido, a arte da flânerie é homóloga ao conhecimento científico, dito em termos de Robert Nisbet, seus agentes são movidos pelo desejo de escapar às pressões da vida cotidiana (cf. Nisbet, 1979). É nesta viagem/deslocamento, guiada pelos ditames do campo científico, que reside a força da imaginação sociológica.

O paralelo com a arte pode ser ainda desdobrado em outro plano. Sabemos que durante o Antigo Regime a pintura e a literatura evoluíam dentro de universos controlados externamente pelo mecenato e pelas exigências políticas (as academias). Por isso Sartre diz que os escritores tinham nesta época dois caminhos possíveis a serem trilhados; ou se conformavam às imposições de uma aristocracia que os sustentava materialmente, ou, enquanto burgueses, tomavam partido contra ela. Em ambos os casos porém o elemento político era determinante, a literatura se encontrava a serviço desta ou daquela classe social (cf. Sartre, 1972). O artista do século XIX rompe com este vínculo de dependência. O ideal de Flaubert, l'art pour l'art, preconiza um tipo de ajustamento no qual as injunções de ordem não estéticas são desconsideradas. O escritor começa a escrever para um público de iniciados pois os critérios relevantes para a apreciação de sua obra passam a ser determinados pelos pares. Afirma-se assim a existência de estruturas intrínsecas ao campo artístico, ou seja, ele se destaca, se separa de outras instâncias existentes na sociedade. No entanto, este processo de autonomização é contemporâneo ao florescimento de uma cultura pautada por leis de um mercado ampliado de bens simbólicos. A emergência do folhetim, do jornal diário, da fotografia, atividades vinculadas ao aspecto produtivo e econômico, põem em causa justamente a autonomia recém conquistada. Daí o desprezo de Flaubert pela literatura folhetinesca a serviço dos grandes jornais. Arte autônoma e utilitarismo burguês são elementos historicamente concomitantes, movimento que afirma tendências antagônicas.

A "arte da flânerie" não escapa a essa contradição. Podemos apreendêla através da oposição entre ócio e trabalho. Benjamin, retomando uma expressão de Marx, nos lembra que na sociedade burguesa a preguiça deixou de ser "heróica"(cf. Benjamin, 1986, p. 990). Ou seja, o lugar que o ócio desfrutava nas sociedades anteriores foi definitivamente deslocado pela preeminência do trabalho. Na França, a Revolução desempenhou um papel semelhante ao puritanismo anglo-saxão. Ao derrotar a nobreza e proscrever a ociosidade ela impulsionou o desenvolvimento da ética do trabalho. O controle do tempo, sinônimo de dinheiro, irá se contrapor às práticas que o desperdiçam. Contenção e ascetismo tornam-se virtudes. O flâneur se contrapõe a esta tendência dominante. Diz Benjamin: "A espontaneidade que tem em comum o estudioso, o jogador e o flâneur é forçosamente a mesma do caçador, isto é, do mais velho gênero de trabalho com afinidades com o ócio" (Benjamin, 1986, p. 998). Da mesma forma que o artista desfruta sua atividade a partir do lazer, oflâneur, na escolha de seu próprio caminho, deve ser autônomo. Sua liberdade não pode estar confina- 
da às exigências estranhas à sua arte. Entretanto, assim como a literatura se vê ameaçada pela proliferação da imprensa e a pintura pela produção industrial da fotografia, oflâneur encontra seu lado obscuro no mundo da fábrica. "O ócio do flâneur é uma demonstração contra a divisão do trabalho"(cf. Benjamin, 1986, p. 557); "AA obsessão de Tylor, de seus colaboradores e de seus sucessores, é uma guerra contra a flânerie"(Benjamin, 1986, p. 567). O ritmo da indústria, para falarmos como Georges Friedmann, promove o trabalho em migalhas, anônimo, intercambiável. O fordismo pressupõe a anulação do indivíduo, sua subordinação a uma engrenagem que o envolve e o ultrapassa. Caminhar, olhar, descrever, tornam-se atos improdutivos.

Seria tentador interpretar a arte da flânerie como uma espécie de crítica à mercantilização do conhecimento. $\mathrm{Na}$ verdade, o processo de autonomização das ciências sociais pode ser visto como homólogo ao do campo da arte. No início elas se confundem com as atividades reflexivas afins: religião, jornalismo, política, filosofia, literatura. Os intelectuais do XIX são marcados pelo ecletismo, mesclando moralismo, saberes, opiniões, que os afastam de um controle mais sistemático da escrita. Por isso Durkheim, na conclusão de $A s$ regras do método sociológico, propõe que a sociologia se transforme numa ciência de caráter esotérico. Sua vocação "flaubertiana" exigia o distanciamento dos interesses alheios ao saber científico. Durkheim atua como um arquiteto, ele delimita um espaço, ergue fronteiras, separando um universo, com regras, objeto e metodologia próprios, distinto do campo difuso do senso comum ou das outras especializações existentes (filosofia, moral, etc.) (cf. Ortiz, 1989). Entretanto, se escrevi a frase no condicional foi porque tenho algumas dúvidas a esse respeito. Um primeiro aspecto deve ser sublinhado. A autonomização do campo das ciências sociais se faz somente no final do século XIX, início do XX. Mesmo assim, sua institucionalização é um processo longo e conflitivo. Durkheim pode ser visto como pai fundador de uma disciplina específica, mas sua proposta, enquanto projeto intelectual, só pode se institucionalizar na França muito mais tarde, com o advento dos institutos de pesquisa, pós-graduação, etc. Quando Benjamin escreve nos anos 30, os intelectuais alemães, apesar dos traumas da I Grande Guerra e do advento do nazismo, ainda são marcados pela idéia de Kultur, isto é, de um espaço autônomo que escapa às imposições da "civilização" material e técnica. Ao contrário de Adorno e de Horkheimer, Benjamin não conheceu a indústria cultural nem o autoritarismo do mercado; para os frankfurtianos, essa dimensão só pode ser incluída em suas preocupações quando eles migram para os Estados Unidos. Aí, a situação era inteiramente outra, este é o momento em que a publicidade, o cinema, o rádio, e logo em seguida a televisão, tornam-se meios potentes de legitimação e de difusão cultural. Quando Adorno trabalha em conjunto com Lazarsfeld, pela primeira vez, ele se dá realmente conta de como o conhecimento se envereda por uma via distinta dos ideais da Kultur. O projeto do Radio Research era teoricamente definido a partir de uma demanda externa (Rockefeller Foundation) fundamentando-se na produção de dados empíricos susceptíveis de serem transformados em informação ${ }^{9}$. Adorno pressentia que toda uma tradição européia, universalizante, perdia
9 Sobre a polêmica entre Adorno e Lazarsfeld consultar: Adorno, 1973; Lazarsfeld, 1969; Pollack, 1979. 
ORTIZ, Renato. Walter Benjamin e Paris - individualidade e trabalho intelectual. Tempo Social; Rev. Sociol. USP, S. Paulo, 12(1): 11-28, maio de 2000.

terreno para uma sociologia que se adequava aos interesses das grandes corporações e do estado. Sua intuição era correta. É nos Estados Unidos que a produção científica começa a ser ditada pelo utilitarismo - tema retomado por Wright Mills na década de 50 (cf. Mills, 1972). Esta dimensão, estrutural à sociedade capitalista moderna, tornou-se hoje um padrão difundido em todos os lugares. Ele torna a flânerie intelectual um ato improdutivo e sem sentido. Este porém é um traço que transcende Paris capital do século XIX, trata-se de uma faceta de um mundo globalizado no qual oflâneur viaja de avião e tem os seus passos mediados pela técnica e pelo mercado. Ele já não é mais um observador da cidade, pois a própria idéia de cidade como um todo integrado se desfez. Ao deslocar-se pelo espaço da modernidade-mundo ele monta um quebra-cabeças constituído de partes de Paris, camadas do Rio de Janeiro, fatias de Nova York. Sua cidade imaginária não corresponde a nenhuma materialidade integrada, suas partes estão disjuntas, espalhadas pelo globo terrestre.

Recebido para publicação em fevereiro/2000

UNITERIMS:

Walter Benjamin, individual, city, flânerie, social sciences, modernity.
ABSTRACT: This paper is an interpretation of Walter Benjamin's 'Paris, Capital of the $19^{\text {th }}$ Century'. Based on the notes Benjamin made on several books he read, mainly during his research at the Bibliotèque Nationale, the author discusses the notion of the individual linking it to two themes. First, to the emergence of the flâneur as a translation of the spirit of mobility which starts with modernity. The discussion on the notion of space, especially where it concerns Paris, is essential for this analysis. The flâneur is seen as an uprooted individual who moves around the remodelled urban space. Second, to the proximity between the act of flânerie and that of intellectual work. Taking flânerie to be intellectual activity, the author shows how the themes of the distancing and the construction of the object are relevant, both to the detective-flâneur and to the reflection in social sciences.

ORTIZ, Renato. Walter Benjamin and Paris - individuality and intelectual work. Tempo Social; Rev. Sociol. USP, S. Paulo, 12(1): 11-28, May 2000. 


\section{REFERÊNCIASBIBLIOGRÁFICAS}

AdoRno. (1973) Experiencias cientificas y Estados Unidos. In: Consignas.Buenos Aires, Amorrortu.

Agulhon, Maurice (org.). (1983) Histoire de la France urbaine. Paris, Seuil.

Agamben, Giorgio. (1986) Cronologia dell'opera e notizie sul testo. In: BENJAMIN, Walter. Parigi capitale del XIX secolo, Torino, Einaudi.

ArIÈs, Philippe. (1971) Histoire des populations françaises. Paris, Seuil.

Benjamin, Walter. (1986) Parigi capitale del XIX secolo. Torino, Einaudi.

Bergeron, Louis (1983) Les voies du grand commerce. In: LeQuin, Yves (org.). Histoire des Français XIXe-XXe siècles. Paris, Armand Colin.

Bourdieu, P., Passeron, J. C. \& Chamboredon, J. C. (1973) Le métier de sociologue. Paris, Mouton.

Bourdieu, Pierre. (1996) As regras da arte. São Paulo, Companhia das Letras.

ChARTIER, Roger. (1978) Les deux Frances: histoire d'une geographie. Cahiers d'Histoire, tomo 23.

Chevalier, Louis. (1984) Classe laborieuses et classes dangereuses à Paris pendant la première moitié du XIXe siècle. Paris, Hachette.

DATz, Pierre. (1894) Histoire de la publicité. Paris, J. Rothschild.

D’Avenel, Georges. (1896) Les mécanismes de la vie moderne. Paris, Colin (tomos I, II, IV), 1896, 1897, 1902.

FARAut, François. (1983) La confection masculine à Paris depuis le $19^{\text {ème }}$ siècle: le cas de la Belle Jardinière. Paris. Tese (Doutorado). École des Hautes Études en Sciences Sociales.

Figuier, Louis. (1989) La photographie au salon de 1859. In: Rouillé, A. (org.). La photographie en France. Paris, Macula.

Fournel, Victor. (1858) Ce qu'on voit dans les rues de Paris. Paris, Adolphe Delahays.

Galabrun, A. Pardaillé. (1983) Les déplacements de parisiens dans la ville au XVIe et XVIIe siècles. Histoire, economie et société, $\mathrm{n}^{\circ} 2$.

GILLE, Bertrand. (1978) Histoire des techniques. Paris, Gallimard.

JARRY, Paul. (1948) Les magasins de nouveautés: histoire retrospective et anédoctique. Paris, A. Barry.

LAZARSFELD, Paul. (1969) An episode in the history of social research. In: Fleming, D. \& BAILYN, B. (orgs.). The intelectual migration: Europe and America, 1930-1960. Cambridge, Harvard University Press.

Le Bon, Gustave. (1980) Psicologia das multidões. Rio de Janeiro, Delraux. 
Levasseur, E. (1912) Histoire du commerce de la France. Paris, Arthur Rousseu.

Messac, Régis. (1972) Le dectetive novel et l'influence de la pensée scientifique. Genève, Slatkine Reprints (primeira edição, 1929).

Miller, Michael. (1987) Au Bon Marché (1869-1920): la consommation apprivoisé. Paris, Colin.

Mills, Wright. (1972) A imaginação sociológica. Rio de Janeiro, Zahar.

Morsel, Henri. (1983) Les grands rythmes économiques du XIX siècle. In: Lequin, Yves (org.). Histoire des Français XIXe-XXe siècles. Paris, Armand Colin.

NADAR. (1900) Quandj'étais photographe. Paris, Flammarion.

Nisbet, Robert. (1979) La sociologia como forma de arte. Madri, EspasaCalpe.

ORTIZ, Renato. (1989) Durkheim: arquiteto e herói fundador. Revista Brasileira de Ciências Sociais, São Paulo, 4(11), outubro 1989. . (1991) Cultura e modernidade. São Paulo, Brasiliense.

ORY, P. (1982) Les expositions universelles à Paris. Paris, Ramsay.

Oster, Daniel \& Goulemot, Jean. (1989) La vie parisiente: anthologie des moeurs du XIXe Siècle. Paris, Sand/Conti.

OusBy, Ian. (1997) The crime and mystery book. Hong Kong, Thames and Hudson.

Pollack, Michael. (1979) Paul Lazarsfeld fondateur d'une multinationale scientifique. Actes de la Recherche en Sciences Sociales, (25), janeiro.

Pronteau, Jeanne. (1966) Les numérotages des maisons de Paris du XVème siècle à nos jours. Paris, Imprimerie Municipale.

RouANET, Sergio Paulo. (1984) Introdução a Walter Benjamin. In: CHAú, Marilena de Souza (org.). Origem do drama barroco alemão. São Paulo, Brasiliense.

SARTRE, Jean Paul. (1972) L'idiot de la famille. Paris, Gallimard.

TARDE, Gabriel. (1989) L'opinion et la foule. Paris, PUF.

Tiedmann, Rolf. (1989) Introdução. In: Benjamin, Walter. Paris capitale du XIXe siècle. Paris, Éditions du Cerf.

Williams, Raymond. (1958) Culture and society. New York, Columbia University Press. 